\title{
Human temporal lobe potentials in verbal learning and memory processes
}

\author{
CHRISTIAN E. ELGER, * THOMAS GRUNWALD, * KLAUS LEHNERTZ,* \\ MARTA KUTAS, $\dagger$ CHRISTOPH HELMSTAEDTER, * ANKE BROCKHAUS, ${ }^{*}$ \\ DIRK VAN ROOST $\$$ and HANS J. HEINZE $\S$
}

\begin{abstract}
*Department of Epileptology, University of Bonn, Bonn, Germany; †Cognitive Science and Neurosciences Departments, University of California, San Diego, U.S.A.; \$Department of Neurosurgery, University of Bonn, Bonn, Germany; and $\S$ Department of Clinical Neurophysiology, University of Magdeburg, Magdeburg, Germany
\end{abstract}

(Received 25 May 1996; accepted 5 October 1996)

\begin{abstract}
Animal experiments and lesion studies have shown the importance of temporal lobe structures for language and memory. We recorded intracranial cognitive potentials from the human lateral and medial temporal lobe in 26 patients with temporal lobe epilepsy undergoing presurgical evaluation, using a word- and a picture-recognition paradigm. Neuropsychological testing included word fluency, verbal reasoning, sustained attention and a verbal learning memory test (VLMT), which was an adapted version of the Rey auditory verbal learning test. Word-specific N400-potentials elicited in the middle temporal gyrus of the dominant left hemisphere (LTL-N400) predicted immediate recall performance after learning, whereas N400s, elicited by words but not pictures in the left anterior medial temporal lobe (AMTL-N400), predicted delayed recall. The number of words that were learned but forgotten after a 30-min delay correlated only with N400s elicited by words in the left anterior medial temporal lobe. Thus, intracranial recordings indicated that different electrophysiological responses in different temporal lobe structures were linked to memory scores from specific neuropsychological tests. (C) 1997 Elsevier Science Ltd.
\end{abstract}

Key Words: event-related potentials; verbal memory; temporal lobe.

\section{Introduction}

Non-invasive scalp recordings of event-related potentials (ERPs) can help to fractionate neuropsychological aspects of language and memory processes [18, 19]. Whereas earlier negative components may reflect cognitive processes relevant for the verbal short-term memory [17], a number of studies described new-minus-old repetition effects with smaller amplitudes of the N400 potential elicited by correctly detected item repetitions in continuous recognition memory tasks [4, 31, 38]. These repetition effects do not differ among various age groups, whereas differences may be found between young children and adults when the size of ERPs elicited by subsequently recognized vs unrecognized items is compared during the acquisition phase [5]. Smith and Halgren demonstrated that repetition effects recorded with scalp electrodes were significantly reduced after temporal

- University Clinic of Epileptology, Sigmund-Freud-Str. 25, 53105 Bonn, Germany; tel.: 0049-228-287-5727; fax: 0049-228287-4328; e-mail: elger@jersey.meb.uni-bonn.de. lobectomy [33], whereas Rugg et al. also found similar effects on the side of the epileptogenic focus in nonresected patients with unilateral temporal lobe epilepsy [32]. These findings suggest that the temporal lobes contribute to the generation of scalp ERPs and repetition effects. The neural substrate of these neurophysiological correlates of cognitive processes can be better identified via invasive recordings of intracranial cognitive potentials in patients with temporal lobe epilepsy (TLE) undergoing presurgical evaluation. Previous studies have identified negative field potentials in the human medial temporal lobe related to the registration of infrequent events (MTL-P300), and the processing of words and pictures in memory and language tasks (MTL-N400) [13, 21, 26-29, 35]. With few exceptions, both these potentials were found to be smaller in the epileptic temporal lobe $[6,22,27,29]$. Various ERPs to words or faces also have been recorded in the neocortex [10-12] and inferior temporal lobe [24]. McCarthy et al. recorded large negative potentials with a peak latency near $400 \mathrm{msec}$ elicited by anomalous sentence-ending words bilaterally in the anterior medial temporal lobe anterior to the hippo- 
campus and near the amygdala (AMTL-N400) [20]. With subdural electrodes positioned near the collateral sulcus just inferior and lateral to the amygdala, they recorded positive potentials at the same latency and concluded that the AMTL-N400 was generated in the neocortex near the collateral sulcus and anterior fusiform gyrus. Nobre and McCarthy showed that this potential was sensitive to semantic priming, that it was larger for words with semantic content (open class or content words) than for words serving grammatical functions (closed class or function words), and that it was not elicited by nonwords [24].

The importance of the left hemisphere in humans for the processing of verbal material has been known for a long time as has that of the temporal lobe for aspects of learning and memory in both humans and non-human animals [1, 3, 16, 23, 34, 36, 37, 39]. Nonetheless, from these studies alone, it has not been possible to determine the extent to which various structures within each temporal lobe contribute to different learning and memory processes. Recording ERPs in patients with temporal lobe epilepsy offers a unique opportunity to fractionate memory processes and to investigate the relationship between structures known to be important in memory and the functions that they subserve, because electrodes are placed in structures relevant for memory processes in both hemispheres, and the high signal-to-noise ratio of intracranial recordings makes it possible to correlate the ERPs in memory-related paradigms with the graded memory deficits of TLE patients.

\section{Materials and methods}

\section{Subjects}

We recorded electrocorticograms (ECoG) and stereo-EEGs (SEEG) from the medial and lateral temporal lobes of 26 patients with pharmacoresistant temporal lobe epilepsy (13 right, 13 left TLE; 10 females; see Tables 1 and 2). Patients ranged in age from 15 to 47 years $($ mean $=26.2$ years $)$, and in the duration of their epilepsy from 1 to 32 years (mean $=16.1$ years).

Multicontact depth- and subdural strip electrodes were implanted as part of the presurgical workup, because the primary epileptogenic area could not be localized by means of non-invasive procedures. Twenty-five patients underwent subsequent epilepsy surgery (two-thirds resection of the temporal lobe, selective amygdalo-hippocampectomy or lesionectomy). Nineteen patients $(76 \%)$ were postoperatively free of seizures, five $(20 \%)$ had improved $(>90 \%$ reduction of seizure frequency), and in one patient, no change in the frequency of seizures occurred. One patient was not operated on because of the unacceptable risk of memory deficits. For all patients, left hemispheric language dominance was determined via the sodium amytal procedure (Wada test). Informed consent was obtained from all patients.

\section{ERP-paradigms and recording procedures}

In two separate blocks, the stimuli were either 300 single visually presented frequent nouns (duration: $200 \mathrm{msec}$ ) or pictures (duration: $400 \mathrm{msec}$ ). In both paradigms, half the stimuli were repeated once, resulting in a total of 450 trials for each. Words were presented once every $1800 \pm 200 \mathrm{msec}$, 75 with a lag of $3 \pm 1$ intervening items and 75 with a delay of $14 \pm 4$ intervening stimuli, and pictures once every $2200 \pm 400 \mathrm{msec}$ with a lag of $4 \pm 1$ intervening stimuli. The patients' task was to indicate whether an item was old or new by pressing one of two buttons. The study was conducted in the (dimly lit) special unit for simultaneous video- and EEG-monitoring with the patient upright in an adjustable bed and facing a monitor approximately $80 \mathrm{~cm}$ away. Pictures were displayed as white line drawings, and words as white characters upon a dark blue rectangular background in the centre of a black screen. ECoG and SEEG were recorded from up to 128 electrode contacts simultaneously and were referenced to extracranially linked mastoids. Data were amplified with a bandpass filter setting of $0.03-85 \mathrm{~Hz}(12 \mathrm{~dB} /$ oct.). After the 12 -bit $\mathrm{A} / \mathrm{D}$ conversion, signals were written continuously to a hard disk using a sampling rate of $173 \mathrm{~Hz}$ per channel. Digital information of stimulusrelevant parameters as well as the patients' reactions were sampled simultaneously. Selective averaging was performed on 1200 -msec stimulus-related epochs containing a $200-\mathrm{msec}$ prestimulus segment. Epochs were rejected in case of false or miss-

Table 1. Patient data and neuropsychological test scores

\begin{tabular}{|c|c|c|c|c|c|c|c|c|c|}
\hline $\begin{array}{l}\text { Patient } \\
\text { ID }\end{array}$ & $\begin{array}{l}\text { Age (duration } \\
\text { of epilepsy) }\end{array}$ & $\begin{array}{l}\text { Surgical } \\
\text { procedure }\end{array}$ & Patholgy & $\begin{array}{l}\text { Immediate } \\
\text { recall }\end{array}$ & $\begin{array}{l}\text { Delayed } \\
\text { recall }\end{array}$ & $\begin{array}{l}\text { Sustained } \\
\text { attention }\end{array}$ & $\begin{array}{l}\text { Verbal } \\
\text { reasoning }\end{array}$ & $\begin{array}{l}\text { Verbal } \\
\text { fluency }\end{array}$ & IQ \\
\hline BJ & $15(10)$ & Lesionectomy & Hamartia & 15 & 15 & 399 & 106 & 25 & \\
\hline $\mathrm{BB}$ & $24(22)$ & SAH & AHS & 12 & 11 & 452 & 89 & 40 & 101 \\
\hline $\mathrm{BF}$ & $34(16)$ & SAH & AHS & 14 & 9 & 507 & 107 & 31 & 108 \\
\hline $\mathrm{CM}$ & $18(04)$ & Lesionectomy & Ganglioglioma & 14 & 12 & 511 & 85 & 21 & 92 \\
\hline DD & $31(18)$ & Lobectomy & AHS & 11 & 13 & 279 & 87 & 27 & 112 \\
\hline HD & $36(22)$ & SAH & AHS & 13 & 9 & 335 & 105 & 25 & 104 \\
\hline $\mathrm{KR}$ & $23(16)$ & $\mathrm{SAH}$ & AHS & 13 & 13 & 484 & 102 & 31 & 93 \\
\hline $\mathrm{KI}$ & $41(29)$ & Lesionectomy & Ganglioglioma & 12 & 11 & 301 & 103 & 29 & 101 \\
\hline LK & $43(28)$ & Lobectomy & AHS & 9 & 3 & 314 & 96 & 31 & 100 \\
\hline MA & $16(06)$ & Lobectomy & Heterotopia & 13 & 9 & 459 & 92 & 22 & 93 \\
\hline NK & $35(18)$ & SAH & AHS & 10 & 2 & 490 & 84 & 15 & 95 \\
\hline VH & $34(32)$ & SAH & AHS & 11 & 9 & 398 & 91 & 28 & 91 \\
\hline WK & $25(02)$ & Lobectomy & Encephalitis & 11 & 7 & 477 & 106 & 35 & 95 \\
\hline
\end{tabular}

The table lists data of patients with right temporal lobe epilepsy.

SAH, selective amygdalo-hippocampectomy; AHS, ammonshornsclerosis).

IQs (HAWIE) are listed where available. 
Table 2. Patient data and neuropsychological test scores

\begin{tabular}{ccllcrrrr}
\hline $\begin{array}{c}\text { Patient } \\
\text { ID }\end{array}$ & $\begin{array}{c}\text { Age (duration } \\
\text { of epilepsy) }\end{array}$ & $\begin{array}{c}\text { Surgical } \\
\text { procedure }\end{array}$ & Patholgy & $\begin{array}{c}\text { Immediate } \\
\text { recall }\end{array}$ & $\begin{array}{c}\text { Delayed } \\
\text { recall }\end{array}$ & $\begin{array}{c}\text { Sustained } \\
\text { attention }\end{array}$ & $\begin{array}{c}\text { Verbal } \\
\text { reasoning }\end{array}$ & $\begin{array}{c}\text { Verbal } \\
\text { fluency }\end{array}$ \\
\hline AR & $28(04)$ & SAH & Hamartia & 8 & 4 & 366 & 97 & 20 \\
BM & $12(03)$ & Lobectomy & AHS & 9 & 5 & 351 & 112 & 18 \\
FD & $21(14)$ & SAH & AHS & 10 & 6 & 452 & 116 & 27 \\
HM & $32(22)$ & Lobectomy & Heterotopia + AHS & 10 & 6 & 390 & 91 & 39 \\
HB & $36(21)$ & SAH & AHS & 11 & 4 & 345 & 93 & 34 \\
HL & $23(14)$ & SAH & AHS & 11 & 6 & 356 & 84 & 25 \\
JB & $42(22)$ & Lesionectomy & Hamartia & 13 & 11 & 335 & 115 & 31 \\
KS & $23(02)$ & Lesionectomy & Ganglioglioma & 11 & 8 & 457 & 81 & 20 \\
KJ & $29(18)$ & No surgery & & 11 & 6 & 301 & 86 & 29 \\
LR & $34(24)$ & SAH & AHS & 10 & 5 & 311 & 94 & 30 \\
MK & $20(16)$ & Lesionectomy & Hamartia & 15 & 15 & 398 & 98 & 25 \\
MR & $39(30)$ & Lobectomy & None & 11 & 7 & 492 & 96 \\
UR & $46(14)$ & SAH & AHS & 13 & 6 & 266 & 97 \\
\hline
\end{tabular}

The table lists data of patients with left temporal lobe epilepsy.

SAH, selective amygdalo-hippocampectomy; AHS, ammonshornsclerosis.

IQs (HAWIE) are listed where available.

ing reactions, or when the ERP-signals were contaminated by epilepsy-specific potentials such as spikes or sharp waves.

\section{Electrode placement and localization}

Bilateral depth electrodes were implanted stereotactically along the longitudinal axis of the hippocampus from an occipital approach with the amygdala as the target for the most anterior electrode. Each catheter-like, 1-mm-thick silastic electrode contained 10 cylindrical contacts of a nickel-chromium alloy $(2.5 \mathrm{~mm})$ every $4 \mathrm{~mm}$. Subdural strip electrodes consisted of 4 - to $2 \times 16$ stainless steel contacts, with a diameter of $2.2 \mathrm{~mm}$, embedded in silastic (interelectrode spacing of $1 \mathrm{~cm}$ ), and were inserted through burr holes. Electrode placements were verified by post-implant computertomography as well as magnetic resonance imaging, and their locations were determined by visual inspection of MRIs with reference to cross-sections published by Duvernoy [2].

\section{Neuropsychological assessment}

Neuropsychological assessment was performed during the non-invasive phase of presurgical evaluation. It included word fluency, verbal reasoning, sustained attention and a verbal learning memory test (VLMT), which was an adapted German version of the Rey auditory verbal learning test [30]; in this test, patients had to learn and recall a list of 15 words (different from those in the ERP-paradigm), which were read to them during each of five consecutive trials. Recall was also tested $30 \mathrm{~min}$ after the fifth trial.

\section{Data analysis and statistics}

ERP components were identified by visual inspection and quantified by latency and amplitude measures. Amplitudes were measured relative to the mean amplitude of a $200-\mathrm{msec}$ prestimulus baseline. For the grand averages, as well as for the correlation and regression analyses, measurements from the site with the largest (word-specific) negativity from 300 to $600 \mathrm{msec}$ in lateral and medial temporal lobe regions of both sides in response to words and pictures were selected. Since repetition effects were well pronounced within a latency range of 300 $700 \mathrm{msec}$, they were quantified by the integral of the new-minusold difference wave within this time window. Multivariate analyses of variance were performed to test the effect of the primary epileptogenic area on ERP-parameters in those patients who were free of seizures after the operation. For each of these measures, bivariate correlations with all neuropsychological performance scores were calculated. Because of multiple comparisons, Bonferroni corrections were applied. Additional partial correlations were calculated as necessary. Using stepwise multiple regression analysis, these measures also were regressed onto the neuropsychological performance scores. Additionally, performance scores in the individual ERPparadigms were correlated with left and right lateral and medial temporal ERP potentials. As the three patients, in whom not all lateral temporal potentials to words and to pictures could be recorded from both sides, did not differ from the rest of the patients in any other respect, all calculations were made using a pairwise deletion in case of missing values.

\section{Results}

\section{Medial temporal lobe}

In all patients, both pictures and words, when seen for the first time, elicited a negative component in the left and right anterior medial temporal lobes peaking around $400 \mathrm{msec}$ (AMTL-N400); upon repetitions, these potentials were somewhat reduced in amplitude at least on the non-epileptogenic side. Latencies of left (mean $=435 \pm$ $73 \mathrm{msec}$ ) and right AMTL-N400s (mean $=439 \pm 72 \mathrm{msec})$ elicited by words were neither significantly different from each other nor correlated. Furthermore, MANOVA showed that the latencies of AMTL-N400s to words were not affected by the side of language dominance or by the side of the primary epileptogenic area. The mean amplitudes of these word-elicited potentials were $57 \pm 24 \mu \mathrm{V}$ on the left and $49 \pm 23 \mu \mathrm{V}$ on the right side. MANOVA revealed a significant influence of the epi- 
leptogenic focus on medial temporal N400 amplitudes $(P<0.05$; post-hoc univariate $F$-test for AMTL-N400: $F=9.36 ; \quad P<0.005)$. For AMTL-N400s to pictures, neither the side of language dominance nor the side of the primary epileptogenic area had any significant influence on latencies (left mean $=420 \pm 66 \mathrm{msec}$; right mean $=$ $419 \pm 73 \mathrm{msec}$ ) or amplitudes (left mean $=68 \pm 27 \mu \mathrm{V}$; right mean $=69 \pm 27 \mu \mathrm{V}$ ). Not only were word-elicited AMTL-N400s reduced in amplitude near epileptogenic foci, but the associated new-minus-old repetition effects also were much attenuated, if not eliminated. The results of a repeated measures ANOVA with the side of the epileptogenic focus (ipsilateral vs contralateral), item repetition (first presentation vs repetition) and stimulus material (verbal vs non-verbal) as within-subject-factors proved that there was a significant interaction between item repetition and the side of the epileptogenic focus $(F=10.44 ; P<0.005)$. Post-hoc $t$-tests for paired samples of ipsilateral and contralateral repetition effects demonstrated significantly lower values on the side of the epileptogenic focus as compared to contralateral measurements for both words (3617 vs $7462 \mathrm{msec} \mu \mathrm{V}$; $t=4.21 ; P<0.0005)$ and pictures (4795 vs $8784 \mathrm{msec} \mu \mathrm{V}$; $t=3.22 ; P<0.005)$. There was no significant interaction between the factor of item repetition and the stimulus material $(F=0.16$; n.s.), nor between those two factors and the side of the primary epileptogenic area. Because of the reduction of repetition effects on the side of the primary epileptogenic area, only nine of our patients had N400 repetition effects in both temporal lobes, admittedly, too small a number to allow reliable correlations with neuropsychological test scores to be made. This may also explain the attenuation of the N400 repetition effect in the ERPs averaged across all subjects, regardless of the side of the lesion. The same sites within the anterior medial temporal lobe on both sides were equally likely to show AMTL-N400s to words and pictures, albeit of larger amplitudes for pictures (repeated measures ANOVA within-subject effect of material: $F=10.44$; $P<0.005$; post-hoc $t$-tests: left $=57$ vs $68 \mu \mathrm{V}, P<0.05$; right $=49$ vs $69 \mu \mathrm{V}, P<0.0005)$. On both sides, maximal AMTL-N400 amplitudes were confined to the most anterior depth electrode contacts situated anterior to the hippocampus proper near the amygdala, comparable to the locations reported by McCarthy et al. [20] and Nobre and McCarthy [25], indicating a localization of possible AMTL-N400 generators near the collateral sulcus. Halgren's data are consistent with an entorhinal generation of this component $[11,12]$. Figure 1 presents typical data from five patients, together with a schematic of their recording sites and the variability of recording sites of the maximal AMTL-N400s for all patients.

\section{Lateral temporal lobe}

Twenty-five out of 26 patients had bilateral subdural electrodes over the temporo-lateral cortices, whereas one patient had a left temporo-parietal grid and no right temporal strip electrodes. In 24 of the remaining patients, both pictures and words elicited a negative component (LTL-N400) in the left and the right middle temporal gyri; these were not affected by the side of language dominance or by the side of the epileptogenic focus. There was one patient who showed right but no left LTL-N400 to pictures. Left LTL-N400s to words were recorded in all 26 patients. Latencies of all left and right lateral potentials were near $400 \mathrm{msec}$ (left LTL-N400 to words: $418 \pm 67 \mathrm{msec}$; right LTL-N400 to words: $408 \pm 63 \mathrm{msec}$; left LTL-N400 to pictures: $435 \pm 68 \mathrm{msec}$; right LTLN400 to pictures: $423 \pm 83 \mathrm{msec}$ ). Mean amplitudes of word-elicited LTL-N400s were $28 \pm 14 \mu \mathrm{V}$ on the left and $26 \pm 18 \mu \mathrm{V}$ on the right side; LTL-N400s to pictures had mean amplitudes of $30 \pm 14 \mu \mathrm{V}$ in the left and $27 \pm 20 \mu \mathrm{V}$ in the right temporal lobe. Repeated measures ANOVA proved a significant within-subject effect of item repetition $(F=7.46 ; P<0.05)$ independent of any interactions with stimulus material or the side of the epileptogenic focus.

Whereas some sites in the lateral temporal lobes generated LTL-N400s (of equal amplitudes) to words and pictures alike, within the left lateral temporal lobe, there were locations in 16 patients that elicited N400s only to words as well as locations in 10 patients in which the N400 to words was clearly more pronounced than the $\mathrm{N} 400$ to pictures. A $t$-test for paired samples of word- and picture-elicited N400s at these sites showed amplitudes of $\mathrm{N} 400$ s to pictures to be significantly smaller ( 10 vs $28 \mu \mathrm{V}$; $t=-3.75 ; P<0.05)$. Within the right temporal lobe, we found five locations in which N400s to words but not to pictures could be recorded. Amplitudes of picture-elicited $\mathrm{N} 400$ s at the sites of best pronounced right temporolateral N400-responses to words were not significantly different from these ( $25 \mathrm{vs} 26 \mu \mathrm{V} ; t=-0.24$; n.s.). The exact location in which a word-specific LTL-N400 could be recorded differed from patient to patient but was always confined to one or, on rare occasions, two electrode contacts (see Fig. 2). As Fig. 3 demonstrates, these contacts were overall more likely to be situated in the posterior third of the middle temporal gyrus.

\section{Correlations between ERPs and performance in ERP- paradigms}

Patients in whom postoperative absence of seizures were consonant with the pre-operative diagnosis of left $(n=9)$ or right TLE $(n=10)$ did not differ with regard to their performance in the recognition paradigms. All 26 patients participating in the study correctly classified a mean of $77 \pm 10 \%$ of all items in the word recognition paradigm (range: 58-92\%). In the picture-recognition paradigm, the range was $47-98 \%$ correct classifications with a mean of $83 \pm 15 \%$. Only left AMTL-N400s to words were correlated with performance in the word recognition task, whereas only right AMTL-N400s to pic- 
A
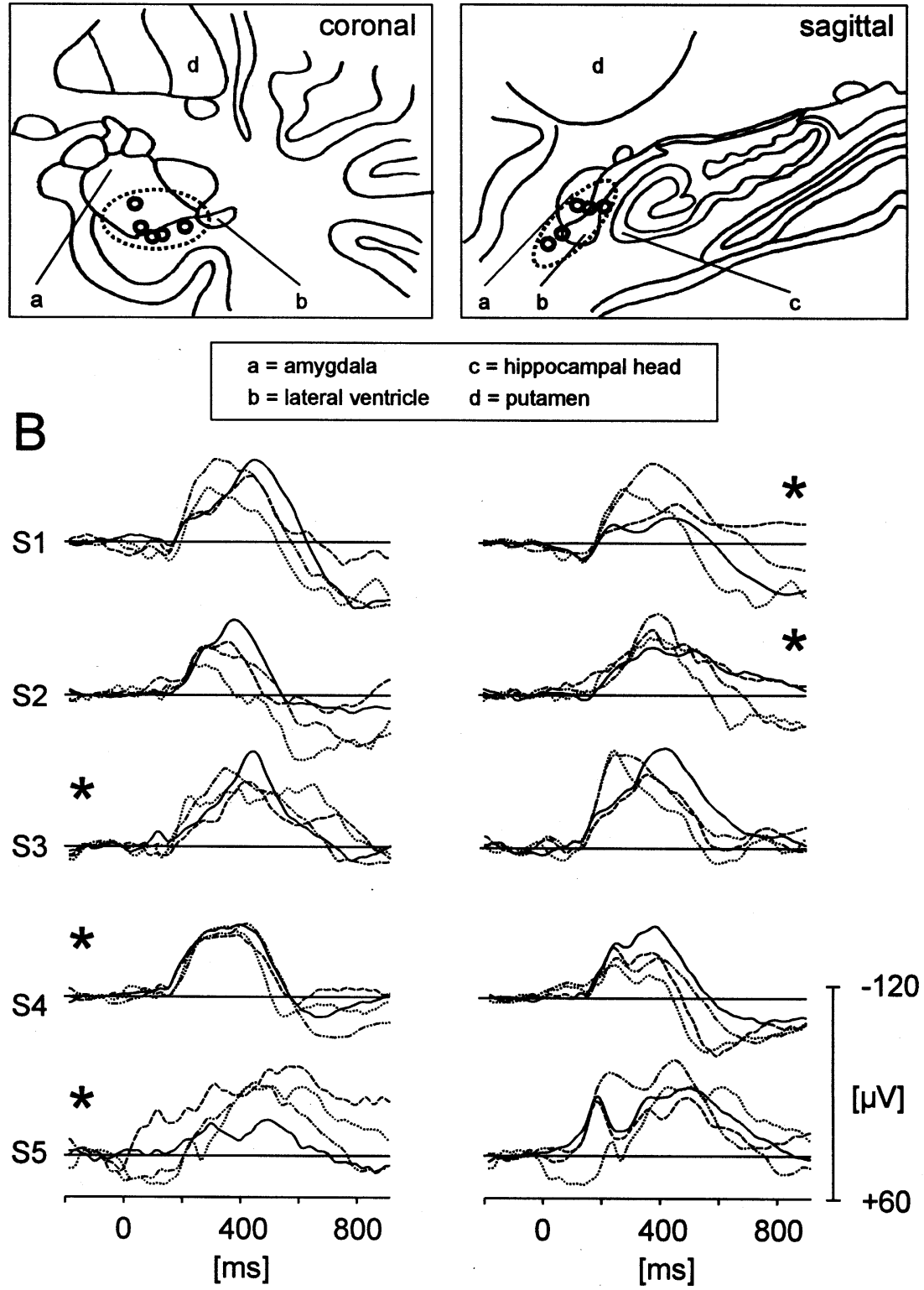

Fig. 1. Electrode locations at which maximal AMTL-N400s were recorded and examples of potentials from five patients. (A) Schematics of left medial temporal recording sites of the maximal AMTL-N400s elicited by words. Circles: recording sites for five patients whose potentials are shown below; dotted ellipses: variability of recording sites of the maximal AMTL-N400s for all patients. The schematics were drawn according to cross-sections published by Duvernoy [2]. (B) Examples of word- and picture-elicited AMTL-N400s in the anterior medial temporal lobes in five patients. Left column: left medial temporal lobe; right column: right medial temporal lobe. Solid line: first presentations of words; dashed line: word repetitions; dashed/dotted line: first presentations of pictures; dotted line: picture repetitions. An asterisk indicates the side of the epileptogenic focus.

tures were correlated with the patients' performance in the picture recognition task (see Table 3).

\section{Correlations between ERPs and neuropsychological performance}

Results of neuropsychological tests are listed in Table 1 for right TLE patients, in Table 2 for patients with left
TLE. Only left but not right lateral and medial temporal N400s correlated with the verbal memory measures (see Fig. 4). These showed no significant correlations with temporal N400s to pictures from either hemisphere (cf. Table 4). Subsequent to Bonferroni corrections necessitated by the multiple number of comparisons, we found that the correlations between left LTL-N400s and immediate verbal recall as well as between left AMTLN400s and delayed verbal recall were significant. Word 
A
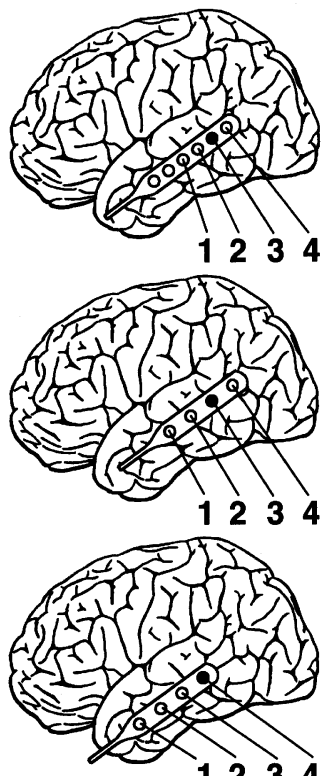

1234
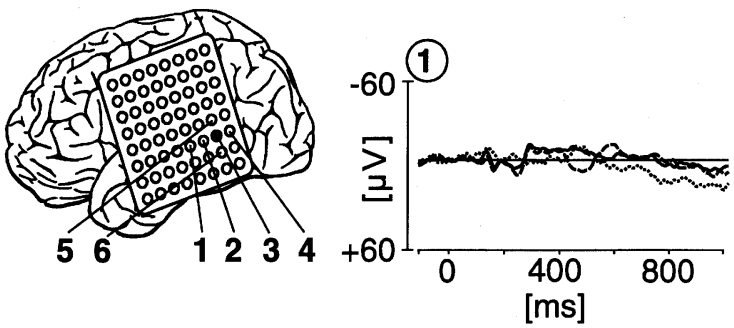

(2)

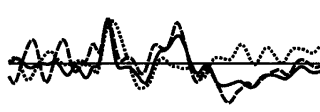

(1)

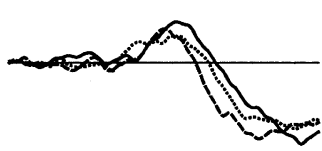

(1)

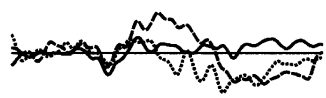

(2)

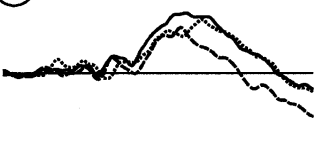

(2)
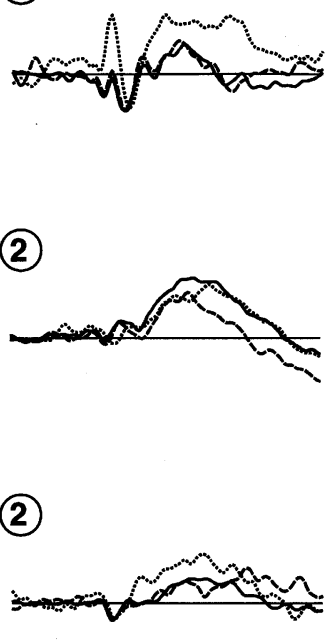

* (4)

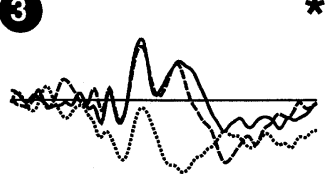

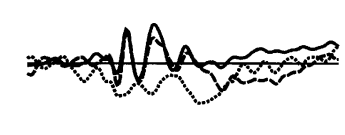

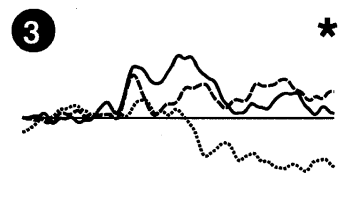

*(4)

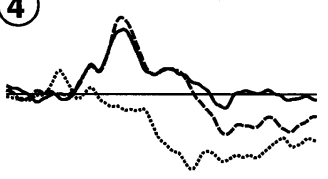

(3)

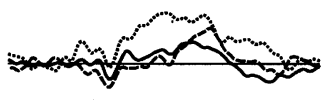

4

(5)

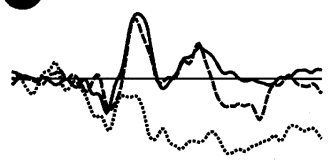

(2)

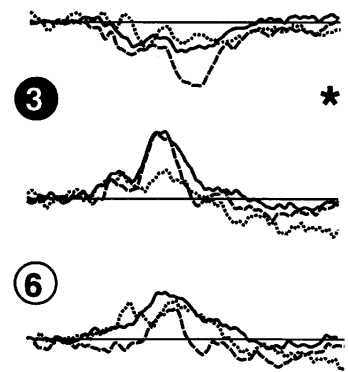

Fig. 2. Examples of typical word-specific LTL-N400s. (A) Schematic of the location of strip- (grid-) electrodes in four patients. Filled circles depict the contact at which the best pronounced N400 to words was recorded. (B) Left lateral ERPs recorded at the selected and adjacent electrode contacts. Numbers refer to electrode contacts from anterior to posterior locations as depicted in (A). Solid line: first presentations of words; dashed line: word repetitions; dotted line: first presentations of pictures. An asterisk indicates the contact with the best pronounced specific response to words.

fluency, verbal reasoning and sustained attention scores were not correlated with any of the ERP components (see Table 4).

Since left AMTL- and LTL-N400s to words were correlated $(r=0.46 ; \quad P<0.05)$, as were immediate and delayed recall $(r=0.79 ; P<0.0005)$, partial correlations were computed. These revealed that, whereas a partial correlation between immediate recall and left LTL-N400s controlling for left AMTL-N400s was significant $(r=0.73 ; P<0.0005)$, that between immediate recall and left AMTL-N400s controlling for left LTL-N400s was not $(r=0.35 ;$ n.s. $)$. Similarly, there was a significant partial correlation between delayed verbal recall and left AMTL-N400s controlling for left LTL-N400s $(r=0.57$;

Table 3. Correlations between left and right lateral and medial temporal N400s and performance in the ERP-paradigms

\begin{tabular}{llll}
\hline ERP paradigm & ERP component & Correct classifications of repetitions & Correct classifications of all items \\
\hline Word recognition & Left LTL-N400 & $r=0.17 ;$ n.s. & $r=0.31 ;$ n.s. \\
& Left AMTL-N400 & $\boldsymbol{r}=\mathbf{0 . 5 8} \boldsymbol{P}<\mathbf{0 . 0 0 5}$ & $\boldsymbol{r}=\mathbf{0 . 5 8} \boldsymbol{P}<\mathbf{0 . 0 0 5}$ \\
& Right LTL-N400 & $r=-0.08 ;$ n.s. & $r=-0.02 ;$ n.s. \\
& Right AMTL-N400 & $r=0.18 ;$ n.s. & $r=0.05 ;$ n.s. \\
Picture recognition & Left LTL-N400 & $r=-0.30 ;$ n.s. & $r=-0.05 ;$ n.s. \\
& Left AMTL-N400 & $r=0.16 ;$ n.s. & $r=0.24 ;$ n.s. \\
& Right LTL-N400 & $r=0.24 ;$ n.s. & $r=0.02 ;$ n.s. \\
& Right AMTL-N400 & $\boldsymbol{r}=\mathbf{0 . 5 2} \boldsymbol{P}<\mathbf{0 . 0 1}$ & $\boldsymbol{r}=\mathbf{0 . 5 5} \boldsymbol{P}<\mathbf{0 . 0 1}$ \\
\hline
\end{tabular}

The table contains bivariate correlation coefficients and significance levels for correlations between left and right LTL- and AMTL-N400s to words and pictures and the recognition rates for repetitions as well as for the rate of correctclassifications of first presentations and repetitions in the word- and picture-recognition paradigms.

Values printed in bold are significant after Bonferroni's correction for multiple comparisons. 
A

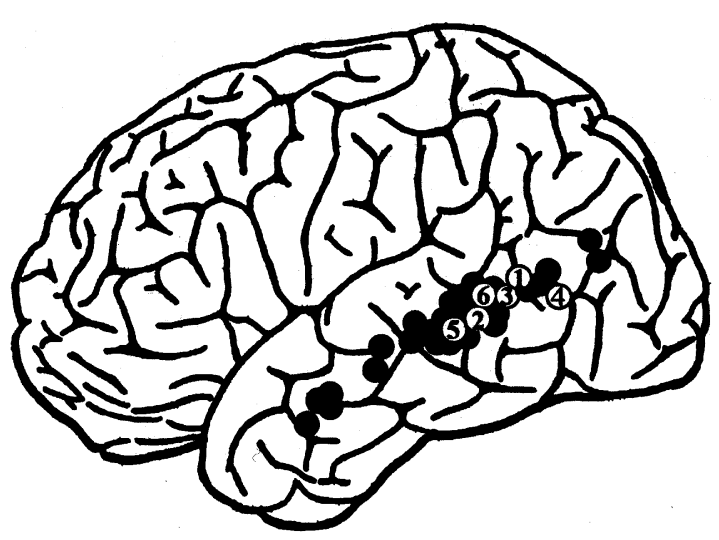

B

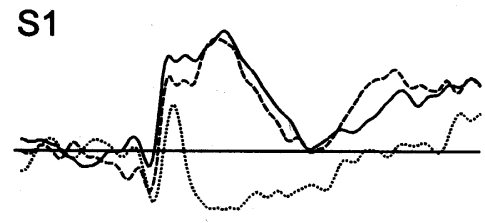

S2
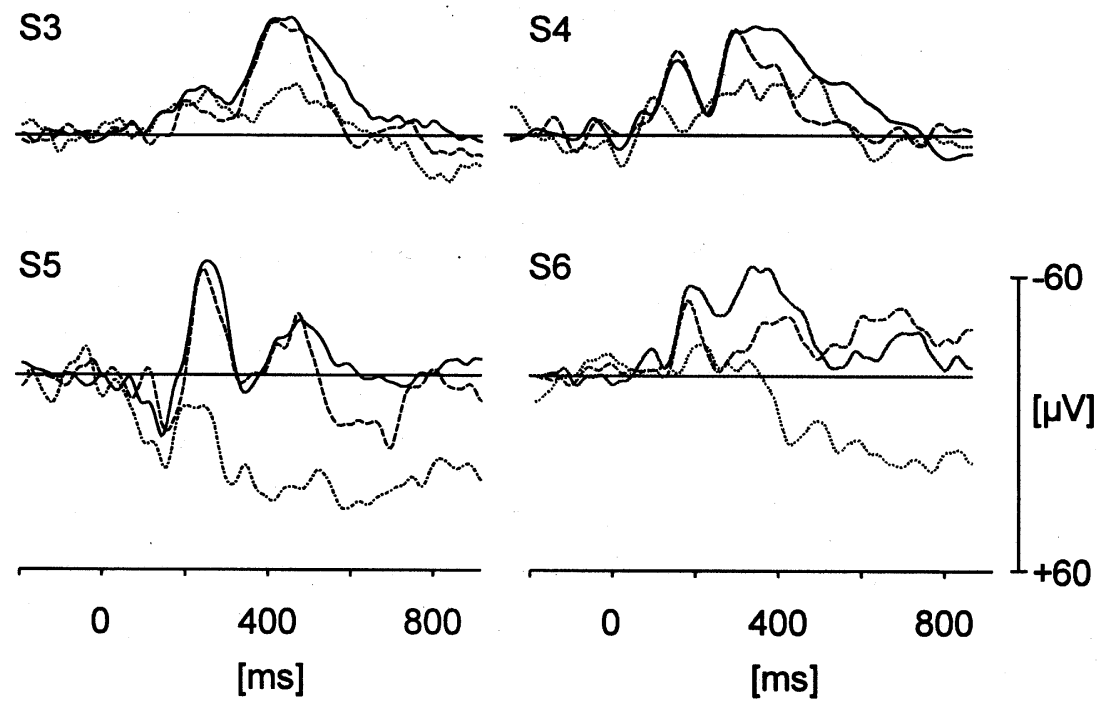

Fig. 3. Electrode locations at which word-specific LTL-N400s were recorded and examples of potentials from six patients. (A) Schematic of the location of electrode contacts in the left middle temporal gyrus at which word-specific LTL-N400s were recorded. White circles: the recording site for each of six patients whose potentials are shown below; black circles: recording sites of the 20 other patients. (B) Examples of left lateral temporal ERPs in six patients. Solid line: first presentations of words; dashed line: word repetitions; dotted line: first presentations of pictures.

Table 4. Correlations between left and right lateral and medial temporal N400s and neuropsychological performance scores

\begin{tabular}{|c|c|c|c|c|c|c|}
\hline ERP paradigm & ERP component & $\begin{array}{l}\text { Immediate verbal } \\
\text { recall (learning) }\end{array}$ & $\begin{array}{l}\text { Delayed verbal } \\
\text { recall }\end{array}$ & $\begin{array}{l}\text { Verbal } \\
\text { fluency }\end{array}$ & $\begin{array}{l}\text { Verbal } \\
\text { reasoning }\end{array}$ & $\begin{array}{l}\text { Sustained } \\
\text { attention }\end{array}$ \\
\hline $\begin{array}{l}\text { Word } \\
\text { recognition }\end{array}$ & $\begin{array}{l}\text { Left LTL-N400 } \\
\text { Left AMTL-N400 } \\
\text { Right LTL-N400 } \\
\text { Right AMTL-N400 }\end{array}$ & $\begin{array}{l}\boldsymbol{r}=\mathbf{0 . 7 5} ; \boldsymbol{P}<\mathbf{0 . 0 0 0 5} \\
r=0.42 ; P<0.05 \\
r=0.10 ; \text { n.s. } \\
r=-0.33 ; \text { n.s. }\end{array}$ & $\begin{array}{l}r=0.42 ; P<0.05 \\
\boldsymbol{r}=\mathbf{0 . 5 9} ; \boldsymbol{P}<\mathbf{0 . 0 0 5} \\
r=0.12 ; \text { n.s. } \\
r=-0.13 ; \text { n.s. }\end{array}$ & $\begin{array}{l}r=0.04 ; \text { n.s. } \\
r=0.34 ; \text { n.s. } \\
r=0.08 ; \text { n.s. } \\
r=-0.11 ; \text { n.s. }\end{array}$ & $\begin{array}{l}r=0.05 ; \text { n.s. } \\
r=-0.08 ; \text { n.s. } \\
r=0.10 ; \text { n.s. } \\
r=-0.10 ; \text { n.s. }\end{array}$ & $\begin{array}{l}r=0.35 ; \text { n.s. } \\
r=-0.03 ; \text { n.s. } \\
r=-0.08 ; \text { n.s. } \\
r=-0.29 ; \text { n.s. }\end{array}$ \\
\hline $\begin{array}{l}\text { Picture } \\
\quad \text { recognition }\end{array}$ & $\begin{array}{l}\text { Left LTL-N400 } \\
\text { Left AMTL-N400 } \\
\text { Right LTL-N400 } \\
\text { Right AMTL-N400 }\end{array}$ & $\begin{array}{l}r=0.11 ; \text { n.s. } \\
r=0.22 ; \text { n.s. } \\
r=-0.03 \text {; n.s. } \\
r=0.08 ; \text { n.s. }\end{array}$ & $\begin{array}{l}r=0.10 ; \text { n.s. } \\
r=0.19 ; \text { n.s. } \\
r=0.13 ; \text { n.s. } \\
r=0.23 ; \text { n.s. }\end{array}$ & $\begin{array}{l}r=-0.19 ; \text { n.s. } \\
r=0.08 ; \text { n.s. } \\
r=0.07 \text { n.s. } \\
r=-0.24 ; \text { n.s. }\end{array}$ & $\begin{array}{l}r=0.12 ; \text { n.s. } \\
r=0.05 ; \text { n.s. } \\
r=0.17 \text {; n.s. } \\
r=-0.19 ; \text { n.s. }\end{array}$ & $\begin{array}{l}r=0.03 ; \text { n.s. } \\
r=0.17 \text { n.s. } \\
r=-0.21 ; \text { n.s. } \\
r=-0.39 ; \text { n.s. }\end{array}$ \\
\hline
\end{tabular}

The table contains bivariate correlation coefficients and significance levels for correlations between left and right LTL- and AMTLN400s to words and pictures and neuropsychological performance scores.

Values printed in bold are significant after Bonferroni's correction for multiple comparisons. 
A
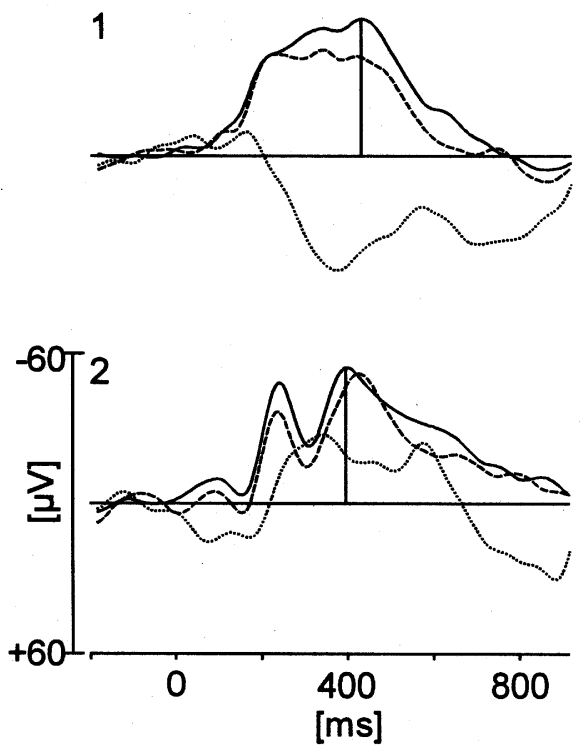

3
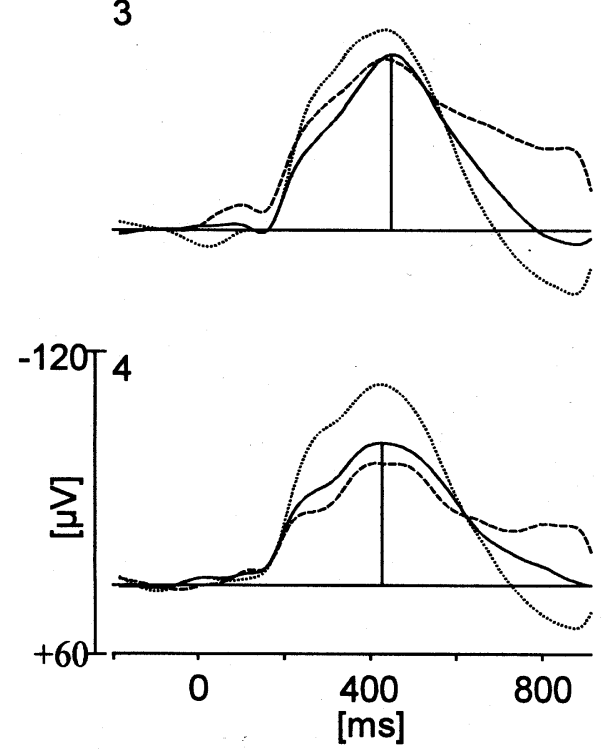

B immediate recall after learning [n]
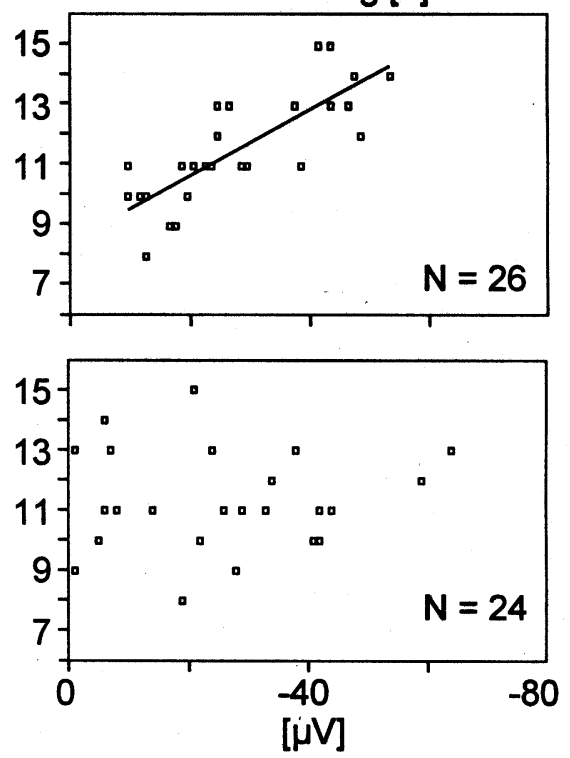

delayed recall $[\mathrm{n}]$
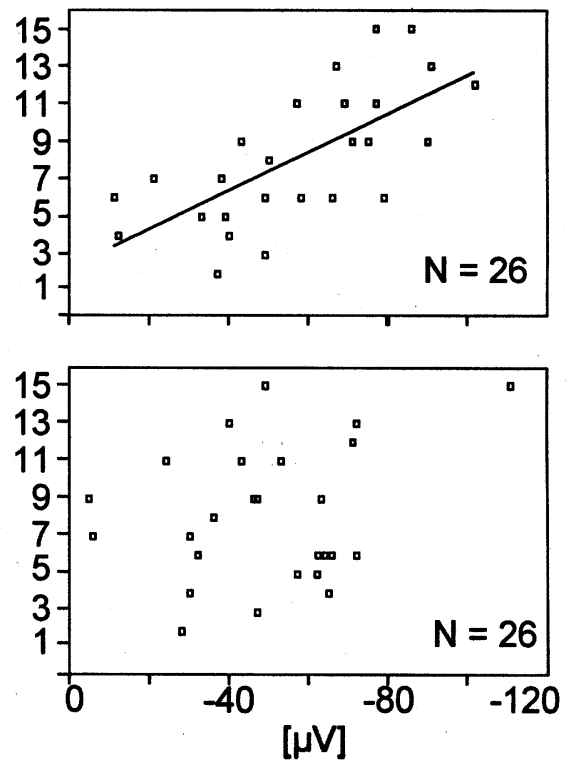

Fig. 4. Grand averages of temporal N400s to words and relations between individual components and verbal memory scores. (A) Grand average event-related potentials (1) left LTL-N400 ( $n=26)$; (2) right LTL-400 $(n=24)$; (3) left AMTL-N400 ( $n=26)$; (4) right AMTL-N400 $(n=26)$. Solid line: first presentations of words; dashed line: word repetitions; dotted line: first presentations of pictures. (B) Associated scatter diagrams of neuropsychological scores regressed onto N400-amplitudes elicited by words. Each of these four measures as well as those of N400s elicited by pictures were regressed onto both the immediate recall of 15 words after the fifth learning trial and recall of the same words after a 30-min delay. Only regressions for N400s elicited by words are shown.

$P<0.005)$ but not between delayed verbal recall performance and left LTL-N400s controlling for left AMTLN400s ( $r=0.38$; n.s.). These selective relations were confirmed by stepwise regression analyses showing that immediate verbal recall could be predicted only by left LTL-N400s, whereas delayed verbal recall could be predicted only by left AMTL-N400s (see Table 5).

An especially sensitive parameter for deficits in verbal memory in TLE patients is the number of words that can be learned but are forgotten across a 30-min delay. As Fig. 5 demonstrates, this neuropsychological parameter was inversely correlated with only left AMTL-N400s $(r=-0.56 ; P<0.005)$ and not with left LTL-N400s $(r=-0.14 ;$ n.s. $)$ or any other N400 elicited by pictures.

\section{Discussion}

Both first presentations of words and pictures elicited negative ERP potentials peaking around $400 \mathrm{msec}$ in the left and right medial and lateral temporal lobes. Amplitudes were generally reduced for repetitions of words and pictures at least in the non-epileptic temporal lobe. 
Table 5. Results of regression analysis: predictors of immediate and delayed verbal recall

\begin{tabular}{llcccc}
\hline Dependent variable & Independent variables & $R$ & $R^{2}$ & $t$-value & $P$ \\
\hline $\begin{array}{l}\text { Immediate verbal recall } \\
\quad \text { (after learning) }\end{array}$ & Left LTL-N400 to words & 0.76 & 0.58 & 5.514 & $<0.00005$ \\
$\quad$ Deft AMTL-N400 to words & & & 1.513 & n.s. \\
$\quad \begin{array}{l}\text { Delayed verbal recall } \\
\quad \text { after 30 min) }\end{array}$ & Left LTL-N400 to words & & & 1.743 & n.s. \\
$\quad$ Verbal memory loss & Left AMTL-N400 to words & 0.63 & 0.40 & 3.851 & $<0.001$ \\
$\quad$ (immediate-delayed recall) & Left AMTL-N400 to words & -0.56 & 0.32 & -3.207 & $<0.005$ \\
\hline
\end{tabular}

The table lists the results of a stepwise multiple regression analysis with immediate and delayed recall as well as memory loss (immediate-delayed recall) as dependent variables and left and right LTL- and AMTL-N400s to words as independent variables using a pairwise deletion in case of missing values.

Left LTL-N400 proved to be predictive of immediate recall, while left AMTL-N400 were shown to be predictive of delayed recall and verbal memory loss.

The $t$-values for both potentials are given for comparison.

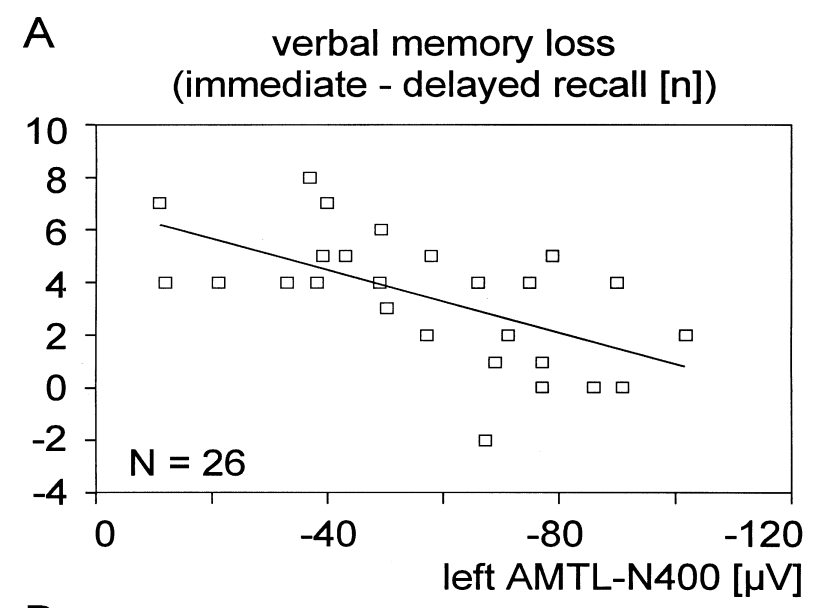

B

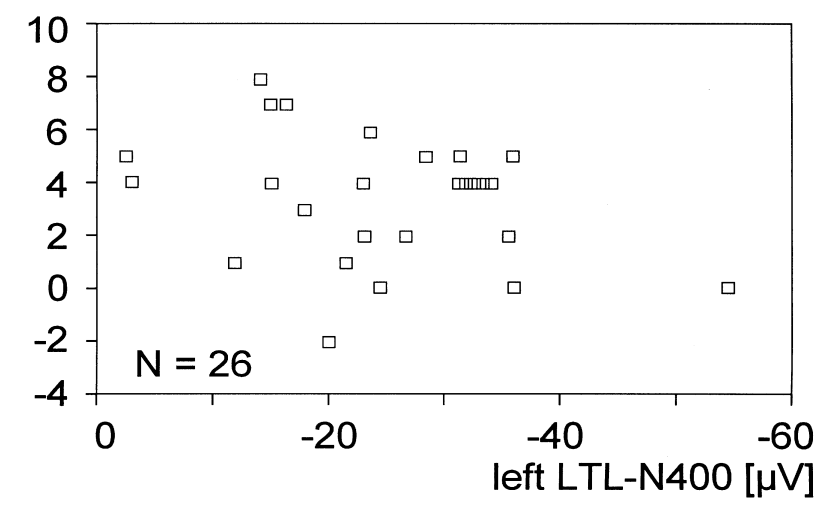

Fig. 5. Scatter diagrams of verbal memory loss, defined as the number of words learned and immediately recalled after the fifth learning trial but not recalled after a 30-min delay, regressed onto left AMTL- and LTL-N400s elicited by words. There was a significant negative correlation between left AMTL-N400s and the number of words that could not be recalled $(r=-0.56 ; P<0.01)$. Bivariate correlations of left LTL- $(r=-0.14)$ and right LTL-N400s $(r=0.01)$ as well as right AMTL-N400s $(r=-0.15)$ elicited by words with verbal memory loss were not significant.

Repetition effects, however, were reduced near epileptogenic foci in the medial temporal lobe, as were AMTL-N400 amplitudes to words. Lateral temporal
N400s to words and pictures were recorded by subdural strip electrodes placed over the left and right middle temporal gyrus. Locations at which only words but not pictures elicited an LTL-N400 were distinctly more frequent in the left temporal lobe. These findings are consistent with the data reported by Guillem et al. who found N400 potentials to pictures exhibiting repetition effects in medial temporal areas as well as the middle temporal gyrus [8], with an attentuation of hippocampal N400 components on the side of the epileptogenic focus [7].

A number of our findings in combination are inconsistent with there being a single surface N400 with a single cerebral generator. These include the observations that: (1) some temporal lobe sites show N400s to words only; (2) only AMTL-N400s to words (not to pictures) are reduced near epileptogenic foci; and (3) only N400 amplitudes from the left side correlate with verbal memory performance. This view that the N400 comprises multiple subcomponents is supported by the work of Guillem et al. [8] and of Halgren et al. on intracranially recorded N400s $[9,11,12]$. It would also fit with the known sensitivity of the surface-N400 potentials to a variety of factors, including word frequency and class, semantic expectancy, repetition and concreteness among others and may account for some of the variability observed in the distributions of N400 effects at the scalp [19]. Guillem et al. provide data supporting the hypothesis that surface $\mathrm{N} 400$ s may represent the summation of a variety of different mechanisms of which they found evidence not only in temporal but also in frontal and parietal regions [8]. The exact relation between surface ERPs and intracranially recorded potentials needs further investigation.

Although we observed N400-like activity to words and to pictures within the medial and lateral temporal regions of the left and right hemispheres, these N400s were characterized by both anatomical and functional specificity. Within the anterior medial temporal lobe on both sides, the same sites were equally likely to show N400s to words and pictures (AMTL-N400), albeit of larger amplitudes for pictures. However, only left AMTL-N400s to words 
correlated with performance in the word recognition paradigm. By contrast, the amplitude of right AMTLN400s to pictures correlated instead with picture recognition performance. In an earlier study with a different group of 25 patients, we obtained a significant correlation between left AMTL-N400s and performance in the word recognition paradigm only in right TLE [6]. Correlation analysis for post-operatively seizure-free left and right TLE patients separately in the present study shows worse correlations for left TLE $(n=9 ; r=0.57$; n.s.) than for right TLE $(n=10 ; r=0.71 ; P<0.05)$. Further studies are needed to evaluate the possible influences of etiology, duration and the patient's age at the onset of the disease on this finding.

As expected, it was activity in the dominant left rather than the non-dominant right hemisphere that predicted performance in all the verbal memory measures. We further found that there was a specialization of various verbal memory functions within the left temporal lobe and that these were reflected in the amplitudes of ERPs during the word recognition task. Specifically, left LTLN400 amplitudes predicted immediate recall scores in verbal learning, whereas left AMTL-N400s to words predicted the number of words that the patients recalled after a 30-min delay. Thus, our results argue for a functional specialization of left lateral and medial temporal structures; immediate recall after the fifth learning trial taps short-term aspects of learning and working memory more than delayed recall and correlates with linguistic skills, whereas the delayed recall measure relates more to longterm verbal memory capacity [14]. Furthermore, verbal memory loss, as defined by the number of words originally learned but forgotten after a 30-min delay, was correlated only with left AMTL- and not LTL-N400 amplitudes. Thus, the middle temporal gyrus seems to be critical in verbal learning and immediate recall; delayed recall of verbal material, which relies on consolidation and retrieval processes, seems to depend more on medial temporal activity reflected in AMTL-N400. This may relate to Halgren's view that, whereas widespread N400complexes index contextual integration, components of the hippocampal formation may index encoding for recent declarative memory $[9,11]$.

Delayed verbal recall performance and especially verbal memory loss are sensitive parameters of the cognitive deficits in patients with left and bilateral temporal lobe epilepsy. Performance in both of these is usually reduced, as are their ipsilateral AMTL-N400 (but not LTL-N400) potentials to words. The fact that only left AMTL-N400s to words predicted verbal memory loss, i.e. the number of words learned but not recalled after delay, whereas no other component was correlated with this performance score, supports the hypothesis that the functioning of the dominant medial temporal lobe may be the limiting factor for verbal memory capacity. This may account for the specific verbal memory deficits of patients with left TLE. However, whereas the epileptogenic process must underlie both the poorer delayed verbal recall and the smaller left medial temporal N400 amplitudes in patients with left or bitemporal lobe epilepsy, this cannot be the whole story. Both the correlations between LTL-N400s and immediate recall and between AMTL-N400s and delayed recall hold, regardless of the side of the lesion.

In summary, our results indicate that lateral temporal and medial temporal structures of the dominant hemisphere subserve different aspects of declarative memory and that these may be further characterized by studies of intracranially recorded event-related potentials. Clinically, the analysis of depth ERPs can help not only to lateralize the epileptogenic focus in TLE but also to make quantitative predictions as to the functional integrity of dominant temporo-lateral and temporo-medial structures for verbal memory. Since right but not left AMTLN400 amplitudes correlated with performance in the picture recognition task, presumably both medial temporal lobes make specific contributions to memory performance [15]. A question for future research is the extent to which one of these structures can compensate for the loss - by lesion or surgical removal - of the other.

Acknowledgements - This work was supported by the Bundesministerium für Bildung und Forschung (BMBF) within the MEDWIS-project and the Deutsche Forschungsgemeinschaft (DFG) within the Sonderforschungsbereich 400.

\section{References}

1. Cave, C. B. and Squire, B. Intact verbal and nonverbal short-term memory following damage to the human hippocampus. Hippocampus 2, 151-163, 1992.

2. Duvernoy, H. M. The Human Hippocampus. Bergmann, Munich, 1988.

3. Eichenbaum, H., Otto, T. and Cohen, N. J. Two functional components of the hippocampal memory system. Behavioral and Brain Sciences 17, 449-518, 1994.

4. Friedmann, D. Cognitive event-related potential (ERP) components during continuous recognition memory for pictures. Psychophysiology 27, 36-148, 1990.

5. Friedmann, D. Event-related potential investigations of cognitive development and aging. Annals of the New York Academy of Sciences 658, 33-64, 1992.

6. Grunwald, T., Elger, C. E., Lehnertz, K., Van Roost, D. and Heinze, H. J. Alterations of intrahippocampal cognitive potentials in temporal lobe epilepsy. Electroencephalography and Clinical Neurophysiology 95, 53-62, 1995.

7. Guillem, F., N'Kaoua, B., Rougier, A. and Claverie, B. Effects of temporal versus extra-temporal lobe epilepsies on hippocampal ERPs: physiopathological implications for recognition memory studies in humans. Cognitive Brain Research 2, 147-153, 1995.

8. Guillem, F., N'Kaoua, B., Rougier, A. and Claverie, B. Intracranial topography of event-related potentials (N400/P600) elicited during a continuous rec- 
ognition memory task. Psychophysiology 32, 382392, 1995.

9. Halgren, E. Physiological integration of the declarative memory system. In The Memory System of the Brain, J. Delacour (Editor), pp. 69-152. World Scientific, Singapore, 1994.

10. Halgren, E., Baudena, P., Clarke, J. M., Heit, G., Liégeois, C., Chauvel, P. and Musolino, A. Intracerebral potentials to rare target and distractor auditory and visual stimuli. I. Superior temporal plane and parietal lobe. Electroencephalography and Clinical Neurophysiology 94, 191-220, 1995.

11. Halgren, E., Baudena, P., Heit, G., Clarke, M. and Marinkovic, K. Spatio-temporal stages in face and word processing. 1. Depth recorded potentials in the human occipital and parietal lobes. Journal of Physiology (Paris) 88, 1-50, 1994.

12. Halgren, E., Baudena, P., Heit, G., Clarke, M., Marinkovic, K. and Chauvel, P. Spatio-temporal stages in face and word processing. 2. Depth-recorded potentials in the human frontal and Rolandic cortices. Journal of Physiology (Paris) 88, 51-80, 1994.

13. Halgren, E., Squires, N. K., Wilson, C. L., Rohrbaugh, J. W., Babb, T. L. and Crandall, P. H. Endogenous potentials generated in the human hippocampal formation and amygdala by infrequent events. Science 210, 803-805, 1980.

14. Helmstaedter, C. and Elger, C. E. Beziehungen zwischen Verbalgedächtnis und Sprachleistungen am Beispiel fokaler Temporallappenepilepsien. Zeitschrift für Geriatrie 1, 1-5, 1992.

15. Helmstaedter, C., Pohl, C., Elger, C. E. Visual learning deficits in nonresected patients with right temporal lobe epilepsy. Cortex 31, 345-355, 1995.

16. Hermann, B. P., Wyler, A. R., Steenman, H. and Richey, E. T. The interrelationship between language function and verbal learning/memory performance in patients with complex partial seizures. Cortex $\mathbf{2 4}$, 245-253, 1988.

17. Kluender, R. and Kutas, M. Bridging the gap: Evidence from ERPs on the processing of unbounded dependencies. Journal of Cognitive Neuroscience 2, 196-214, 1993.

18. Kutas, M. and Hillyard, S. A. Reading senseless sentences: Brain potentials reflect semantic incongruity. Science 207, 203-205, 1980.

19. Kutas, M. and Van Petten, C. Psycholinguistics electrified. Event-related brain potential investigations. In Handbook of Psycholinguistics, M. Gernsbacher (Editor), pp. 83-143. Academic Press, San Diego, 1994.

20. McCarthy, G., Nobre, A. C., Bentin, S. and Spencer, D. D. Language-related field potentials in the anterior medial temporal lobe: I. Intracranial distribution and neural generators. Journal of Neuroscience 15, 1080-1089, 1995.

21. McCarthy, G., Wood, C. C., Williamson, P. D. and Spencer, D. D. Task-dependent field potentials in human hippocamapal formation. Journal of Neuroscience 9, 4253-4268, 1989.

22. Meador, K. J., Loring, D. W., King, D. W., Gallagher, B. B., Gould, M. J., Flanigin, H. F. and
Smith, J. R. Limbic evoked potentials predict site of focus. Neurology 37, 494-497, 1987.

23. Milner, B. Disorders of learning and memory after temporal lobe lesions in man. Clinical Neurosurgery 19, 421-426, 1972.

24. Nobre, A. C., Allison, T. and McCarthy, G. Word recognition in the human inferior temporal lobe. Nature 372, 260-263, 1994.

25. Nobre, A. C. and McCarthy, G. Language-related field potentials in the anterior medial temporal lobe: II. Effects of word type and semantic priming. Journal of Neuroscience 15, 1090-1098, 1995.

26. Paller, K. A., McCarthy, G., Roessler, E., Allison, T., Wood, C. C. Potentials evoked in human and monkey medial temporal lobe during auditory and visual oddball paradigms. Electroencephalography and Clinical Neurophysiology 84, 269-279, 1992.

27. Puce, A., Andrewes, D. G., Berkovic, S. F. and Bladin, P. F. Visual recognition memory. Neurophysiological evidence for the role of white matter in man. Brain 114, 1647-1666, 1991.

28. Puce, A. and Bladin, P. F. Scalp and intracerebral P300 in surgery for temporal lobe epilepsy. Clinical and Experimental Neurology 24, 85-89, 1987.

29. Puce, A., Kalnins, R. M., Berkovic, S. F. and Bladin, P. F. Limbic P3 potentials, seizure localization, and surgical pathology in temporal lobe epilepsy. Annals of Neurology 26, 377-385, 1989.

30. Rey, A. L'examen de Clinique en Psychologie. Presses Universitaires des France, Paris, 1964.

31. Rugg, M. D. and Nagy, M. E. Event-related potentials and recognition memory for words. Electroencephalography and Clinical Neurophysiology $\mathbf{7 2}$, 395-406, 1989.

32. Rugg, M. D., Roberts, R. C., Potter, D. D., Pickles, C. D. and Nagy, M. E. Event-related potentials related to recognition memory. Effects of unilateral temporal lobectomy and temporal lobe epilepsy. Brain 11, 2313-2332, 1991.

33. Smith, M. E. and Halgren, E. Dissociation of recognition memory components following temporal lobe lesions. Journal of Experimental Psychology, Learning, Memory and Cognition 15, 50-60, 1989.

34. Smith, M. and Milner, B. The role of the right hippocampus in the recall of spatial location. Neuropsychologia 19, 781-793, 1981.

35. Smith, M. E., Stapleton, J. M. and Halgren, E. Human medial temporal lobe potentials evoked in memory and language tasks. Electroencephalography and Clinical Neurophysiology 63, 145-159, 1986.

36. Squire, L. R. Memory and the hippocampus: A synthesis from findings in rats, monkeys and humans. Psychological Review 99, 195-231, 1992.

37. Squire, L. R. and Zola-Morgan, S. The medial temporal lobe memory system. Science 253, 1380-1386, 1991.

38. Van Petten, C., Kutas, M., Kluender, R., Mitchiner, M. and McIsaac, H. Fractionating the word repetition effect with event-related potentials. Journal of Cognitive Neuroscience 3, 131-150, 1991.

39. Zola-Morgan, S. and Squire, L. R. The primate hippocampal formation: evidence for a time-limited role in memory storage. Science 250, 288-290, 1990. 